\title{
Bireylerin E-Sağlık Okuryazarlığı ve Siberkondri Düzeylerinin İncelenmesi
}

\author{
SERKAN DENIZ \\ serkand100@gmail.com \\ ORCID ID: 0000-0002-8093-1336
}

Öz: İnternetten sağlıkla ilgili bilgilere hızlı ve kolay bir şekilde ulaşabilmek mümkün hale gelmiştir. Bu durum e-sağlık okuryazarlı̆̆ ve siberkondri kavramlarını günümüzde önemli hale getirmiştir. Bu çalışma ile bireylerin e-sağlık okuryazarlı̆̆ ve siberkondri düzeylerinin demografik özelliklere göre farklllı gösterip göstermediğinin; ayrıca e-sağlık okuryazarlığ ile siberkondri düzeyleri arasındaki ilişkinin belirlenmesi amaçlanmıştır. Araştırma, Aralık 2019Ocak 2020 aylarında İstanbul'da gerçekleştirilmiştir. Araştırma sonucunda katılımcıların yaşına, eğitim durumuna, medeni durumuna ve çalışma durumuna göre e-sağlik okuryazarlık düzeylerinin istatistiksel olarak farklılık göstermediği; ancak katılımcıların cinsiyetine göre e-sağlik okuryazarlık düzeylerinin istatistiksel olarak farklılık gösterdiği belirlenmiştir. Katılımcıların cinsiyetine, yaşına, medeni durumuna ve çalışma durumuna göre siberkondri düzeylerinin istatistiksel olarak farklllı göstermediği; ancak katılımcıların eğitim durumuna göre siberkondri düzeylerinin istatistiksel olarak farklılık gösterdiği belirlenmiştir. E-sağllk okuryazarlı̆̆ı ile siberkondri düzeyleri arasında pozitifyönlü ve düşük düzeyde bir ilişki olduğu belirlenmiştir.

Anahtar Kelimeler: E-Sağlık okuryazarlığı, Siberkondri, İnternet, Sağlık.

\section{Giriş̧}

Sağlık hizmetlerinin sunumunda yaşanan değişimler bireylerin sağlıklarıyla ilgili sorumluluklarını arttırmıştır. ${ }^{1} \mathrm{Bu}$ sorumlulukla beraber teknolojik gelişmelere bağlı olarak bireylerin bilgiye hızlı ve kolay bir şekilde ulaşabilmesi, sürekli bilgiye maruz kalması, ${ }^{2}$ sağlık hizmetlerinin çeşitlenmesi ve sayısının artması, sağlık hizmetlerine erişimin kolaylaşması gibi birçok sebepten dolayı sağlık okuryazarlığı günümüzde daha da önemli hale gelmiştir. Sağlık okuryazarlığı, bireylerin sağlıklarını koruması, geliştirmesi ve bozulan sağlıklarını iyileştirmesi için temel sağlık bilgilerini edinebil-

\footnotetext{
* Dr. Öğr. Üyesi, Yalova Üniversitesi, Termal Meslek Yüksekokulu.

1 Medine Yılmaz ve Zeliha Tiraki, “Sağlık Okuryazarlığı Nedir? Nasıl Ölçülür?”, Dokuz Eylül Üniversitesi Hemşirelik Fakültesi Elektronik Dergisi, 9:4 (2016), s.146.

2 Seçil Utma, "Sağlık Okuryazarlığı Kavramı ve Sağlık Haberlerini Doğru Okumak", IBAD Sosyal Bilimler Dergisi, 5 (2019), s.226.
} 
mesi, yorumlayabilmesi ve anlayabilmesi açısından önemlidir. ${ }^{3}$

İnternet sağlıkla ilgili araştırma yapmak ve bilgi edinmek için günümüzde önemli bir kaynak haline gelmiştir. Bu durum sağlık okuryazarlığının farklı bir hali olan e-sağlık okuryazarlığının önem kazanmasına neden olmuştur. E-sağlık okuryazarlığı elektronik kaynaklarda yer alan sağlık bilgilerine yönelik bir kavramdır. İnternetin sağlıkla ilgili araştırma yapmak ve bilgi edinmek için önemli bir kaynak haline gelmesi ile beraber önem kazanan başka bir kavram da siberkondridir. Bireyler sağlık durumlarıyla ilgili bilgi edinmek, endişelerini gidermek veya rahatlamak için internette çeşitli araştırmalar yapabilirler. Ancak bu araştırmalar sonucunda internetten edinilen bilgiler bireylerin kaygı ve endişelerinin daha da artmasına ve bağlı olarak internette sağlık durumlarıyla ilgili daha çok ve daha uzun süren araştırmalar yapmasına neden olabilir. Bu durum siberkondri kavramı ile açıklanmaktadır.

$\mathrm{Bu}$ çalışma ile bireylerin e-sağlık okuryazarlığı ve siberkondri düzeylerinin demografik özelliklere göre farklılık gösterip göstermediğinin; ayrıca e-sağlık okuryazarlığ 1 ile siberkondri düzeyleri arasındaki ilişkinin belirlenmesi amaçlanmıştır.

\section{Sağlık Okuryazarlığı ve E-Sağlık Okuryazarlığı}

Sağlık okuryazarlığı, iyi sağlığı teşvik etmek ve sürdürebilmek için bireylerin bilgiye erişebilme, bilgiyi anlayabilme ve kullanabilme becerisini ve motivasyonunu belirleyen bilişsel ve sosyal becerilerdir. ${ }^{4}$ Başka bir tanıma göre sağlık okuryazarlığı, bireylerin sağlıkları ile ilgili bilinçli seçimler yapmak, sağlık risklerini azaltmak ve yaşam kalitelerini arttırmak için, sağlıkla ilgili bilgi ve kavramları aramaya, anlamaya, değerlendirmeye ve kullanmaya yönelik sahip olduğu beceri ve yetkinliklerdir. ${ }^{5}$ Diğer bir tanıma göre sağlık okuryazarlığı, bireylerin sağlık bilgilerini okuma, anlama ve uygun sağlık kararları vermek için kullanma yeteneğidir. ${ }^{6}$

Herhangi bir ilacın hangi dozda alınması gerektiği, tahlil sonuçlarının, tansiyon ve şeker ölçümündeki rakamların ne anlama geldiği, bazı alışkanlıkların getirdiği risklerin bilincinde olmak gibi birçok konu sağlık okuryazarlığ ${ }_{1}$ ile yakından ilişkilidir. ${ }^{7}$ Sağlık okuryazarlığ zarlığının yetersizliği, bireylerin sağlık hizmetleri hakkında bilgi eksikliklerine, tıbbi bilgileri anlamamalarına, sağlık durumlarının kötü olduğunu anlayamamalarına, koruyucu sağlık hizmetlerini daha az kullanmalarına, tedavi ağırlıklı hizmetlere daha fazla yönelmelerine, gereksiz hastane başvuruları ile sağlık talebinin artması-

3 Özlem İbrahimoğlu, Hülya Saray Kılıç ve Sevinç Mersin, "Fabrika Çalışanlarının Sağlık Okuryazarlığı Düzeyleri ve Etkileyen Faktörler: Bilecik İli Örneği”, Sağglk ve Toplum, 3 (2019), s.29.

4 Don Nutbeam, Health Promotion Glossary, Geneva: World Health Organization, 1998, s.10; T.C. Sağllk Bakanlığı Temel Sağlık Hizmetleri Genel Müdürlüğü, Sağllğın Teşviki ve Geliştirilmesi Sözlüğü, Ankara: T.C. Sağlık Bakanlığı Temel Sağlık Hizmetleri Genel Müdürlüğü, 2011, s.10

5 Christina Zarcadoolas, Andrew Pleasant ve David S. Greer, "Understanding Health Literacy: An Expanded Model”, Health Promotion International, 20:2 (2005), s.196-197.

6 Joanne G Schwartzberg vd., "Communication Techniques for Patients with Low Health Literacy: A Survey of Physicians, Nurses, and Pharmacists", American Journal of Health Behavior, 31:1 (2007), s.S96.

7 Utma, "Sağllk Okuryazarlığı", s.228.

8 Jennifer A. Manganello, "Health Literacy and Adolescents: A Framework and Agenda for Future Research", Health Education Research, 23:5 (2008), s.840. 
na, sağlık profesyonelleriyle iletişim sorunları yaşamalarına, hastalıklarının ilerleyen aşamalarında sağlık hizmetlerini kullanmalarına, uygulanan tedaviyi anlamamalarına, tedavi önerilerine uymamalarına, öz bakım yetersizliğine, ilaç kullanım hatalarına, sağlık giderlerinde artışa, morbidite ve mortalite oranlarında artışa neden olabilmektedir. ${ }^{9}$

Günümüzde hemen hemen her konuda olduğu gibi sağlık konusunda da internet önemli bir bilgi kaynağı haline gelmiştir. Bu durum sağlık okuryazarlığının farklı bir hali olan e-sağlık okuryazarlığının önem kazanmasına neden olmuştur. E-sağlık okuryazarlığı, elektronik kaynaklarda sağlık bilgilerini araştırmak, bulmak, anlamak, değerlendirmek ve edinilen bilgiyi sağlık problemlerinin ele alınması veya çözülmesi için kullanabilme/uygulayabilme becerisi olarak tanımlanmaktadır. ${ }^{10}$

Güven, Bulut ve Öztürk'ün araştırmasına göre katılımcıların sağlıkla ilgili bilgilere ulaşmak için kullandıkları en önemli kaynağın internet olduğu belirlenmiştir. ${ }^{11}$ TÜİK’in araştırmasına göre de 2019 yılının son üç ayında ülkemizde internet kullananların \%69,3'ü interneti sağlıkla ilgili bilgi araştırmak için kullanmışlardır. ${ }^{12}$ İnternetin sağlıkla ilgili bilgi edinmek ve araştırmak için bu derece yaygın kullanılmasına karşın Can ve diğerlerinin sağlığı ilgilendiren konularda kullanılan ve belli kriterlere göre seçilmiş olan web sitelerine yönelik yaptıkları araştırma kapsamında inceledikleri web sitelerinin büyük bir kısmının kanıta dayalı bilgiler içermediği, kaynaklarının güncelliğinin belirtilmediği ve uzman görüşü içermediği belirlenmiştir. ${ }^{13}$ İnternetin sağlıkla ilgili bilgilere erişim için çok yoğun bir şekilde kullanılmasına karşın internette yer alan sağlık bilgilerinin güvenirliğinin tartışılması e-sağlık okuryazarlığının önemini ortaya koymaktadır. E-sağlık okuryazarlığının düşük olması bireylerin internette durumları ile ilgili doğru bilgilere ulaşamamalarına ve ulaşılan yanlış bilgilere inanarak yanlış teşhise, tedaviye ve sağlık davranışlarına yönelmelerine neden olabilmektedir. ${ }^{14}$

\section{Siberkondri}

Sağlık konusunda internetin önemli bir bilgi kaynağı haline gelmesi ile beraber önem kazanan diğer bir kavram da siberkondridir. Siberkondri, bedensel duyumların farklı yorumlanmasından kaynaklanan korku ve endişe olarak tanımlanan hipokondri

\footnotetext{
9 Miranda R. Andrus ve Mary T. Roth, "Health Literacy: A Review", Pharmacotherapy: The Journal of Human Pharmacology and Drug Therapy, 22:3 (2002), s.291; Ayșegül Ilgaz ve Sebahat Gözüm, "Tamamlayıcı Sağllk Yaklaşımlarının Güvenilir Kullanımı için Sağlık Okuryazarlığının Önemi”, Dokuz Eylül Üniversitesi Hemşirelik Fakültesi Elektronik Dergisi, 9:2 (2016), s.74; Mahmut Akbolat vd., "Sağlık Okuryazarlığı Hasta-Hekim İlişkisini Etkiler mi?: Sakarya İlinde Bir Araştırma”, TAF Preventive Medicine Bulletin, 15:4 (2016), s.356; Anne-Linda Frisch vd., "Defining and Measuring Health Literacy: How Can We Profit from Other Literacy Domains?", Health Promotion International, 27:1 (2011), s.117.

10 Cameron D. Norman ve Harvey A. Skinner, "eHealth Literacy: Essential Skills for Consumer Health in a Networked World”, Journal of Medical Internet Research, 8:2:e9 (2006), s.2.

11 Durdane Yılmaz Güven, Hülya Bulut ve Sercan Öztürk, "Sağlık Bilimleri Fakültesi Öğrencilerinin Sağllk Okuryazarlığı Düzeylerinin İncelenmesi”, Journal of History Culture and Art Research, 7:2 (2018): s.404.

12 TÜİK, erişim 9 Ocak, 2020, http://www.tuik.gov.tr/PreTablo.do?alt_id=1028.

13 Abdullah Buğra Can vd., "Sağlık Arama Davranışı Olarak İnternet Kullanımını İnceleyen Bir Araştırma", Cumhuriyet Tip Dergisi, 36:4 (2014), s.490.

14 Can vd., "Sağlık Arama”, s.491.
} 
kavramının internet ortamına yansımış hali olarak değerlendirilmektedir. ${ }^{15}$ Siberkondri, sağlık konusunda yaşanan kaygı ve endişeler nedeniyle sağlık bilgisi araştırmak için yapılan; ancak yaşanan kaygı ve endişeleri daha da arttıran, internetteki aşırı veya tekrarlanan aramalar olarak tanımlanmaktadır. ${ }^{16}$ Siberkondri, sağlıkla ilgili araştırma yapmak için internette çok fazla zaman geçirmeyi ve bunun sonucunda da sağlıkla ilgili duyulan kaygıda yaşanan artışı içeren bir kavramdır. ${ }^{17}$ Siberkondri zihinsel bir hastalık değildir. Sağlık kaygısı ve hipokondrinin bir parçası olarak ortaya çıkan bir davranıştır. ${ }^{18}$

Günümüzde internet kullanımının artmasıyla beraber bireyler sağlık sorunlarıyla ilgili internette sık sık araştırmalar yapmaya başlamışlardır. ${ }^{19}$ Bireyler fayda sağlama amacı ile internette sağlık bilgileri araştırırken bu davranışları ile zarar görme olasılıklarını da arttırmaktadırlar. ${ }^{20}$ İnternette yer alan sağlık bilgilerinin çelişkili, belirsiz ve yanlış olması ya da bireylerin hiç bilmediği hastalık ve sağlık bilgilerine de erişebilmesi nedeni ile internetten yapılan araştırmalar bireylerin sağlık konusundaki kaygı ve endişelerini arttırabilmekte ${ }^{21}$ ve rahatlamak için internette defalarca kez aramalar yapmalarına neden olabilmektedir. Sağlıkla ilgili duyulan kaygı ve endişelerini hafifletmek için yapılan bu tekrarlayıcı aramalar bireylerin kaygı ve endișelerinin daha da şiddetlenmesine neden olabilmektedir. ${ }^{22} \mathrm{Bu}$ durum beraberinde siberkondriyi getirmektedir.

Siberkondri yaşayan kişilere siberkondriyak denilmektedir. Siberkondriyaklar kendi bedenlerinde meydana gelen belirtileri internette araştırarak benzer belirtileri olan ciddi hastalıkların kendilerinde de olduğunu düşünerek kaygı ve endişeye kapılabilmektedirler. Örneğin siberkondriyak bir kişi göğüs bölgesinde ağrı hissettiği zaman, kalp krizi geçirdiğini veya kalp yetmezliği yaşadığını düşünebilmekte ve kendi kendine koyduğu teşhisle hastaneye başvurabilmektedir. Yapılan test ve tetkikler sonucunda herhangi bir hastalığı olmadığı ortaya çıksa bile kaygı ve endişe yaşabilmektedir. Siberkondri; hastanelerin yoğunluğunun ve iş yükünün artması, kaynak israfı, kişinin zamanını boşa harcaması ve yanlış tedavilere yönelmesi gibi olumsuz sonuçlara neden olabilmektedir. ${ }^{23}$

15 Kemal Elciyar ve Deniz Taşçı, "Siberkondri Ciddiyet Ölçeği’nin Anadolu Üniversitesi İletişim Bilimleri Fakültesi Öğrencilerine Uygulanması”, Abant Kültürel Araştırmalar Dergisi, 2:4 (2017), s. 231.

16 Vladan Starcevic ve David Berle, "Cyberchondria: Towards a Better Understanding of Excessive HealthRelated Internet Use”, Expert Review of Neurotherapeutics, 13:2 (2013), s.206.

17 Ryan D. McMullan vd., "The Relationships between Health Anxiety, Online Health Information Seeking, and Cyberchondria: Systematic Review and Meta-Analysis”, Journal of Affective Disorders, 245 (2019), s.271.

18 Starcevic ve Berle, “Cyberchondria: Towards", s.211.

19 Ali Görkem Gençer vd., “DSM-5’e Giremeyen Tanılar (Kompulsif Satın Alma, Misophonia, Facebook Kıskançlı̆̆ı, Pagofaji, Siberkondria, İnternet Bağımlılı̆̆ı)”, Türkiye Klinikleri Psikiyatri-Özel Konular, DSM-5’in Yeni Tanıları Özel Sayısı (2018), s.89.

20 Ayşegül Durak Batıgün vd., "Siberkondriya Ölçeği (SİBKÖ): Geliştirme, Geçerlik ve Güvenirlik Çalışması", Dusunen Adam The Journal of Psychiatry and Neurological Sciences, 31:2 (2018), s.149.

21 Vladan Starcevic, "Cyberchondria: Challenges of Problematic Online Searches for Health-Related Information”, Psychotherapy and Psychosomatics, 86:3 (2017), s.130.

22 Selma Altındiş vd., "Üniversite Çalışanlarında Siberkondria Düzeyleri ve İlişkili Faktörlerin İncelenmesi”, Sakarya Tip Dergisi, 8:2 (2018), s.360.

23 Derya Altınışık, “İnternet Çağının Hastalığı: Siberkondri”, erişim 10 Ocak, 2020, https://www.bilimvetekno. com/internet-caginin-hastaligi-siberkondri/ 


\section{Yo̊ntem}

Araştırma, Aralık 2019 - Ocak 2020 aylarında İstanbul'da gerçekleştirilmiştir. Araştırmada veri toplamak için anket yöntemi kullanılmıştır.

\section{Evren ve O̊rneklem}

Araştırma evrenini, İstanbul'da oturan ve 18 yaşını doldurmuş bireyler oluşturmuştur. Araştırma evrenini temsil edebilecek örneklem büyüklügü \%95 güven aralığında 384 kişi olarak belirlenmiş olup; örnekleme yöntemi olarak kolayda örnekleme yöntemi kullanılmıştır. Araştırma kapsamında 438 anket formu toplanmış; ancak geçerli olan 394 anket formu değerlendirilmeye alınmıştır.

\section{Veri Toplama Araçları}

Araştırmada veri toplamak için üç bölümden oluşan anket formu kullanılmıştır. Anket formunun ilk bölümde araştırmaya katılanların demografik özelliklerinin belirlenmesine yönelik sorular yer almaktadır. Anket formunun ikinci bölümünde, katılımcıların e-sağlık okuryazarlık düzeylerinin belirlenmesine yönelik ifadeler yer almaktadır. Bu bölümde Norman ve Skinner tarafından geliştirilen ve 8 ifadeden oluşan "E-Sağlık Okuryazarlığ Ölçeği”" kullanılmıştır. ${ }^{24}$ Ölçeğin Türkçe geçerlilik ve güvenirlik çalışması Coşkun ve Bebiş tarafından yapılmıştır. ${ }^{25} \mathrm{Bu}$ araştırma kapsamında yapılan analize göre ölçeğin güvenilir olduğu belirlenmiştir $(\alpha=0,88)$. Ölçekte yer alan ifadeler, 5’li Likert tipi ölçek seçenekleri ile ölçülmüştür. Ölçekten elde edilecek ortalama puanın 5’e yaklaşması e-sağlık okuryazarlık düzeyinin arttığını gösterdiğinden değerlendirmeler bu yönde yapılmıştır.

Anket formunun üçüncü bölümünde ise, katılımcıların siberkondri düzeylerinin belirlenmesine yönelik ifadeler yer almaktadır. Bu bölümde McElroy ve Shevlin tarafından geliştirilen "Siberkondri Ciddiyet Ölçeği” kullanılmıştır. ${ }^{26}$ Ölçek, zorlantı (8 ifade), aşırı kaygı (8 ifade), aşırılık (8 ifade), içini rahatlatma (6 ifade) ve doktora güvensizlik ( 3 ifade) olmak üzere 5 boyuttan ve 33 ifadeden oluşmaktadır. Ölçeğin Türkçe geçerlilik ve güvenirlik çalışması Uzun tarafından yapılmıştır. ${ }^{27} \mathrm{Bu}$ araştırma kapsamında yapılan analize göre ölçeğin güvenilir olduğu belirlenmiştir $(\alpha=0,90)$. Ölçekte yer alan ifadeler, 5’li Likert tipi ölçek seçenekleri ile ölçülmüştür. Ölçekten elde edilecek ortalama puanın 5’e yaklaşması siberkondri düzeyinin arttığını gösterdiğinden değerlendirmeler bu yönde yapılmıştır.

24 Cameron D. Norman ve Harvey A. Skinner, "eHEALS: The eHealth Literacy Scale”, Journal of Medical Internet Research, 8:4:e27 (2006), s.4.

25 Sabahat Coşkun ve Hatice Bebiş, “Adolesanlarda E-Sağlık Okuryazarlığı Ölçeği: Türkçe Geçerlik ve Güvenirlik Çalışması”, Gülhane Tip Dergisi, 57 (2015).

26 Eoin McElroy ve Mark Shevlin, "The Development and Initial Validation of the Cyberchondria Severity Scale (CSS)", Journal of Anxiety Disorders, 28:2 (2014).

27 Süleyman Utku Uzun, "Pamukkale Üniversitesi Çalışanlarında Siberkondri Düzeyi ve Etkileyen Etmenler", Uzmanlık Tezi, T.C. Pamukkale Üniversitesi, 2016. 


\section{Verilerin Analizi}

Veri analizlerinde, e-sağlık okuryazarlığı ve siberkondri düzeyini belirlemek için tanımlayıcı istatistikler hesaplanmıştır. E-sağlık okuryazarlığı ve siberkondri düzeylerinin katılımcıların demografik özelliklerine göre istatistiksel olarak farklılık gösterip göstermediğinin belirlenmesinde, Kolmogorov-Smirnov testi sonucunda verilerin normal dağılımdan geldiği belirlendiğinden $(\mathrm{p}>0,05)$ iki bağımsız grubun karşılaştırılmasında bağımsız örneklemler için t-testi, ikiden fazla bağımsız grubun karşılaştırılmasında ise, tek yönlü varyans analizleri (ANOVA) yapılmıştır. Tek yönlü varyans analizi sonucunda ortaya çıkan farklılıkları belirlemek için tamamlayıcı olarak LSD testi kullanılmıştır. E-sağlık okuryazarlığı ile siberkondri arasındaki ilişkiyi belirlemek için de Pearson korelasyon analizi yapılmıştır. Elde edilen bulgular \%95 güven aralığında ve \%5 anlamlılık düzeyinde değerlendirilmiştir.

\section{Bulgular}

Araştırma sonucunda elde edilen bulgulara aşağıda yer verilmiştir.

Tablo 1. Demografik Özelliklerin Dağılımı $(n=394)$

\begin{tabular}{|l|l|c|c|}
\hline \multicolumn{2}{|c|}{ Demografik Özellikler } & n & $\%$ \\
\hline \multirow{4}{*}{ Cinsiyet } & Erkek & 139 & 35,3 \\
\cline { 2 - 4 } & Kadın & 255 & 64,7 \\
\hline \multirow{4}{*}{ Yaş } & $\leq 25$ & 211 & 53,6 \\
\cline { 2 - 4 } & $26-35$ & 105 & 26,6 \\
\cline { 2 - 4 } & $\geq 36$ & 78 & 19,8 \\
\hline \multirow{4}{*}{ Eğitim Durumu } & Lise veya Altı & 125 & 31,7 \\
\cline { 2 - 4 } & Önlisans & 126 & 32,0 \\
\cline { 2 - 4 } & Lisans veya Lisansüstü & 143 & 36,3 \\
\hline \multirow{2}{*}{ Medeni Durum } & Bekar & 268 & 68,0 \\
\cline { 2 - 4 } & Evli & 126 & 32,0 \\
\hline \multirow{2}{*}{ Çalışma Durumu } & Evet & 226 & 57,4 \\
\cline { 2 - 4 } & Hayır & 168 & 42,6 \\
\hline
\end{tabular}

Araştırmaya katılanlara ilişkin demografik özellikler Tablo 1'de gösterilmiştir. Tabloya göre araştırmaya katılanlardan 139 kişi $(\% 35,3)$ erkek, 255 kişi de $(\% 64,7)$ kadındır. Katılımcılardan 211 kişinin $(\% 53,6) 25$ veya altı yaş aralığında, 105 kişinin (\%26,6) 26-35 yaş aralığında, 78 kişinin de $(\% 19,8) 36$ veya üzeri yaş aralığında yer aldığı belirlenmiştir. Katılımcılardan 125 kişinin $(\% 31,7)$ lise veya altı, 126 kişinin $(\% 32,0)$ önlisans, 143 kişinin de $(\% 36,3)$ lisans veya lisansüstü eğitim düzeyine sahip olduğu belirlenmiştir. Katılımcılardan 268 kişi $(\% 68,0)$ bekar, 126 kişi de $(\% 32,0)$ evlidir. Katılımcılardan 226 kişi $(\% 57,4)$ bir işte çalışırken, 168 kişi ise $(\% 42,6)$ herhangi bir işte çalışmamaktadır. 
Tablo 2. Değişkenlere İlişkin Tanımlayıcı İstatistikler

\begin{tabular}{|l|c|c|c|}
\hline Değişkenler & $\mathbf{n}$ & Ort. & Std. Sapma \\
\hline E-Sağlık Okuryazarlığı & 394 & 3,30 & 0,75 \\
\hline Siberkondri & 394 & 2,41 & 0,57 \\
\hline
\end{tabular}

Tablo 2'ye göre e-sağllk okuryazarlık düzeyinin orta düzeyde $(3,30 \pm 0,75)$, siberkondri düzeyinin ise düşük düzeyde $(2,41 \pm 0,57)$ olduğu belirlenmiştir.

Tablo 3. E-Sağlık Okuryazarlı̆̆ ve Siberkondri Düzeylerinin Demografik Özelliklere Göre Karşılaştırılması

\begin{tabular}{|c|c|c|c|c|c|c|c|c|}
\hline \multirow{2}{*}{\multicolumn{2}{|c|}{ Demografik Özellikler }} & \multirow{3}{*}{$\begin{array}{c}\mathbf{n} \\
139\end{array}$} & \multicolumn{3}{|c|}{ E-Sağlık Okuryazarlığı } & \multicolumn{3}{|c|}{ Siberkondri } \\
\hline & & & \multirow{2}{*}{$\begin{array}{l}\text { Ort. } \\
3,19\end{array}$} & \multirow{2}{*}{$\begin{array}{c}\begin{array}{c}\text { Std. } \\
\text { Sapma }\end{array} \\
0,76\end{array}$} & & Ort. & $\begin{array}{l}\text { Std. } \\
\text { Sapma }\end{array}$ & \\
\hline \multirow{2}{*}{ Cinsiyet } & Erkek & & & & \multirow{2}{*}{$\begin{array}{l}t=-2,07 \\
p=0,04\end{array}$} & 2,44 & 0,55 & \multirow{2}{*}{$\begin{array}{l}\mathrm{t}=0,65 \\
\mathrm{p}=0,52\end{array}$} \\
\hline & Kadın & 255 & 3,35 & 0,73 & & 2,40 & 0,58 & \\
\hline \multirow{3}{*}{ Yaş } & $\leq 25$ & 211 & 3,33 & 0,76 & \multirow{3}{*}{$\begin{array}{l}F=2,35 \\
p=0,10\end{array}$} & 2,43 & 0,56 & \multirow{3}{*}{$\begin{array}{l}F=1,91 \\
p=0,15\end{array}$} \\
\hline & $26-35$ & 105 & 3,16 & 0,71 & & 2,47 & 0,59 & \\
\hline & $\geq 36$ & 78 & 3,37 & 0,75 & & 2,31 & 0,56 & \\
\hline \multirow{3}{*}{$\begin{array}{l}\text { Eğitim } \\
\text { Durumu }\end{array}$} & Lise veya Altı (1) & 125 & 3,22 & 0,75 & \multirow{3}{*}{$\begin{array}{l}F=1,36 \\
p=0,26\end{array}$} & 2,49 & 0,59 & \multirow{3}{*}{$\begin{array}{c}\mathrm{F}=3,92 \\
\mathrm{p}=0,02 \\
\text { Fark }=1>3, \\
2>3\end{array}$} \\
\hline & Önlisans (2) & 126 & 3,38 & 0,76 & & 2,45 & 0,55 & \\
\hline & $\begin{array}{l}\text { Lisans veya Lisan- } \\
\text { süstü (3) }\end{array}$ & 143 & 3,29 & 0,73 & & 2,31 & 0,55 & \\
\hline \multirow{2}{*}{$\begin{array}{l}\text { Medeni } \\
\text { Durum }\end{array}$} & Bekar & 268 & 3,31 & 0,75 & \multirow{2}{*}{$\begin{array}{l}\mathrm{t}=0,71 \\
\mathrm{p}=0,48\end{array}$} & 2,43 & 0,54 & \multirow{2}{*}{$\begin{array}{l}t=1,06 \\
p=0,29\end{array}$} \\
\hline & Evli & 126 & 3,26 & 0,74 & & 2,37 & 0,62 & \\
\hline \multirow{2}{*}{$\begin{array}{l}\text { Çalışma } \\
\text { Durumu }\end{array}$} & Evet & 226 & 3,24 & 0,79 & \multirow{2}{*}{$\begin{array}{l}\mathrm{t}=-1,58 \\
\mathrm{p}=0,12\end{array}$} & 2,40 & 0,59 & \multirow{2}{*}{$\begin{array}{l}\mathrm{t}=-0,63 \\
\mathrm{p}=0,53\end{array}$} \\
\hline & Hayır & 168 & 3,36 & 0,69 & & 2,43 & 0,53 & \\
\hline
\end{tabular}

Tablo 3'de katılımcıların demografik özelliklerine göre e-sağlık okuryazarlığı ve siberkondri düzeylerinin karşılaştırılması yer almaktadır. Tabloya göre katılımcıların yaşına, eğitim durumuna, medeni durumuna ve çalışma durumuna göre e-sağllk okuryazarlık düzeylerinin istatistiksel olarak farklılık göstermediği $(\mathrm{p}>0,05)$; ancak katılımcıların cinsiyetine göre e-sağlık okuryazarlık düzeylerinin istatistiksel olarak farklılık gösterdiği belirlenmiştir ( $<<0,05)$. Kadın katılımcıların e-sağlık okuryazarlık düzeyinin erkek katılımcılara göre yüksek olması farklılığın nedenini ortaya koymaktadır. Yine tabloya göre katılımcıların cinsiyetine, yaşına, medeni durumuna ve çalışma durumuna göre siberkondri düzeylerinin istatistiksel olarak farklılık göstermediği ( $p>0,05)$; ancak katılımcıların eğitim durumuna göre siberkondri düzeylerinin istatistiksel olarak farklılık gösterdiği belirlenmiştir $(\mathrm{p}<0,05)$. 
Tablo 4. E-Sağlık Okuryazarlı̆̆ı ile Siberkondri İlişkisi

\begin{tabular}{|l|c|c|}
\hline \multicolumn{2}{|c|}{} & Siberkondri \\
\hline \multirow{3}{*}{ E-Sağlık Okuryazarlığı } & $\mathbf{r}$ & 0,16 \\
\cline { 2 - 3 } & $\mathbf{p}$ & 0,00 \\
\cline { 2 - 3 } & $\mathbf{n}$ & 394 \\
\hline
\end{tabular}

Tablo 4’e göre e-sağlık okuryazarlığ ile siberkondri düzeyleri arasında istatistiksel olarak anlamlı bir ilişki vardır $(\mathrm{p}<0,05)$. Korelasyon katsayısına göre $(\mathrm{r}=0,16)$, e-sağlık okuryazarlığı ile siberkondri düzeyleri arasında pozitif yönlü ve düşük düzeyde bir ilişki vardır.

\section{Tartışma ve Sonuç}

$\mathrm{Bu}$ araştırma sonucunda katılımcıların e-sağlık okuryazarlık düzeylerinin, orta düzeyde olduğu belirlenmiştir. Teknolojide yaşanan gelişmeler ve internete erişimin artması ile beraber bireyler yoğun bir şekilde bilgiye maruz kalmakta ve internetten istedikleri her türlü bilgiye hızlı ve çok kolay bir şekilde ulaşabilmektedirler. Ancak internetten ulaşılan bu bilgilerin bir kısmı doğru iken bir kısmı da eksik, yanıltıcı ve yanlış olabilmektedir. Özellikle sağlık konusunda ulaşılan eksik, yanıltıcı ve yanlış bilgiler hem bireye hem de topluma geri dönüşü olmayan büyük zararlar verebilmektedir. Böylesi bir durumla karşılaşmamak için e-sağlık okuryazarlığı düzeyinin daha da yükseltilmesi gerekmektedir. Araştırma sonuçlarına göre katılımcıların siberkondri düzeylerinin, düşük düzeyde olduğu belirlenmiştir. Siberkondrinin bireylerin kaygı ve endişelerini arttırması ve yanlış tedaviye yönlendirmesi, ilerleyen dönemlerde bir hastalığa dönüşmesi, hem bireysel hem de toplumsal kaynakların israfı gibi olumsuz etkileri düşünüldügünnde araştırma ile ulaşılan bu sonuç istenilen bir sonuçtur ve bu sonucun daha da düşürülmesi önerilmektedir.

Araştırma ile katılımcıların cinsiyetine göre e-sağlık okuryazarlık düzeylerinin istatistiksel olarak farklılık gösterdiği, katılımcıların yaşına, eğitim durumuna, medeni durumuna ve çalışma durumuna göre e-sağlık okuryazarlık düzeylerinin istatistiksel olarak farklılık göstermediği belirlenmiştir. Ertaş, Kıraç ve Demir'in yapmış oldukları benzer araştırmanın bulgularına göre de e-sağlık okuryazarlık düzeylerinin katılımcıların cinsiyetine, yaşına ve eğitim durumuna göre istatistiksel olarak farklılık gösterdiği belirlenmiştir. ${ }^{28}$

Araştırma bulguları incelendiğinde, kadın katılımcıların erkek katılımcılara göre; 36 veya üzeri yaş aralığında yer alan katılımcıların diğer yaş gruplarında yer alan katılımcılara göre; önlisans eğitim durumuna sahip katılımcıların diğer eğitim durumuna sahip katılımcılara göre; bekar katılımcıların evli katılımcılara göre; herhangi bir işte çalışmayan katılımcılarında çalışan katılımcılara göre e-sağlık okuryazarlık düzeylerinin daha yüksek olduğu belirlenmiştir.

28 Handan Ertaş, Ramazan Kıraç, Rahime Nur Demir, “Dijital Okuryazarlık ve E-Sağlık Okuryazarlığı Arasındaki İlişkinin İncelenmesi” (3.Uluslararası 13.Ulusal Sağlık ve Hastane İdaresi Kongresi Bildiri Kitabı, Sakarya Üniversitesi, Sakarya, Ekim 10-13, 2019). 
Araştırma ile katılımcıların cinsiyetine göre siberkondri düzeylerinin istatistiksel olarak farklılık göstermediği belirlenmiştir. Bu sonuç Altındiş ve diğerlerinin araştırma bulguları ile benzerlik gösterirken, Tiritoğlu'nun araştırma bulguları ile benzerlik göstermemektedir. ${ }^{29}$ Katılımcıların eğitim durumuna göre siberkondri düzeylerinin istatistiksel olarak farklılık gösterdiği belirlenmiştir. Bu sonuç Tiritoğlu'nun ve Uzun'un araştırma bulguları ile benzerlik gösterirken, Altındiş ve diğerlerinin araştırma bulguları ile benzerlik göstermemektedir. ${ }^{30}$ Katılımcıların yaşına ve medeni durumuna göre siberkondri düzeylerinin istatistiksel olarak farklılık göstermediği belirlenmiştir. Altındiş ve diğerlerinin ve Uzun'un araştırmalarında ise, katılımcıların yaşına göre siberkondri düzeylerinin istatistiksel olarak farklılık gösterdiği; ancak katılımcıların medeni durumuna göre siberkondri düzeylerinin istatistiksel olarak farklılık göstermediği belirlenmiştir. ${ }^{31}$ Katılımcıların çalışma durumuna göre siberkondri düzeylerinin istatistiksel olarak farklılık göstermediği belirlenmiştir. Bu sonuç Tiritoğlu'nun araştırma bulguları ile benzerlik göstermektedir. ${ }^{32}$

Araştırma bulguları incelendiğinde, kadın katılımcıların erkek katılımcılara göre; 36 veya üzeri yaş aralığında yer alan katılımcıların diğer yaş gruplarında yer alan katılımcılara göre; lisans veya lisansüstü eğitim durumuna sahip katılımcıların diğer eğitim durumuna sahip katılımcılara göre; evli katılımcıların bekar katılımcılara göre; çalışan katılımcıların herhangi bir işte çalışmayan katılımcılara göre siberkondri düzeylerinin daha düşük olduğu belirlenmiştir.

$\mathrm{Bu}$ araştırma ile ulaşılan başka bir sonuç ise, e-sağlık okuryazarlığ́ ile siberkondri düzeyleri arasında istatistiksel olarak anlamlı, pozitif yönlü ve düşük düzeyde bir ilişkinin olduğudur. Başka bir ifade ile e-sağlık okuryazarlık düzeyindeki artış, düşükte olsa siberkondri düzeyinin de artmasına neden olmaktadır. Bu durumun internette geçirilen süre ile ilgili olduğu düşünülmektedir. Ergün, Kızıl Sürücüler ve Işık'ın yapmış oldukları araştırma bulgularına göre internet kullanım süresi ile e-sağlık okuryazarlığı arasında anlamlı bir ilişki saptanmış ve internet kullanım süresi yüksek olan katılımcıların daha yüksek e-sağlık okuryazarlık düzeyine sahip olduğu belirlenmiştir. ${ }^{33}$ Bu sonuçlar çerçevesinde e-sağlık okuryazarlık düzeyi yüksek olan bireylerin internette daha fazla vakit geçirdiği ve bu durumunda düşük düzeyde de olsa siberkondri düzeyini arttırdığı söylenebilir. Ayrıca e-sağlık okuryazarlık ile siberkondri arasındaki ilişkinin derinlemesine araştırılması önerilmektedir.

Araştırma sonuçları çerçevesinde e-sağlık okuryazarlığı düzeyinin arttırılması için halka yönelik eğitim programlarının düzenlenmesi, sağlık kurumlarının web sayfa-

29 Altındiş vd., "Üniversite Çalışanlarında”, s.363; Sena Tiritoğlu, "Diyetisyene Başvuran Bireylerin Beslenme ve Diyet Hakkındaki Düşünceleri ile Siberkondri İlişkisi”, Yüksek Lisans Tezi, T.C. Okan Üniversitesi Sağlık Bilimleri Enstitüsü, 2019, s.17

30 Tiritoğlu, "Diyetisyene Başvuran”, s.17; Uzun, "Pamukkale Üniversitesi”, s.55; Altındiş vd., "Üniversite Çalışanlarında”, s.363.

31 Altındiş vd., "Üniversite Çalışanlarında”, s.363; Uzun, “Pamukkale Üniversitesi”, s.55.

32 Tiritoğlu, "Diyetisyene Başvuran”, s.17.

33 Sibel Ergün, Hale Kızıl Sürücüler, Reyhan Işık, "Ergenlerde e-Sağlık Okuryazarlığı ve Sağlıklı Yaşam Biçimi Davranışları: Balıkesir Örneği”, JAREN, 5:3 (2019), s.199-201. 
larında e-sağlık okuryazarlığını arttırmaya yönelik bilgilerin verilmesi, okul müfredatlarında sağlık okuryazarlığını geliştirmeye yönelik derslere yer verilmesi önerilmektedir. Siberkondri düzeyinin düşürülmesi için de, internetteki sağlık bilgilerinin içeriğini denetlemek ve yanıltıcı veya yanlış bilgi paylaşımlarının önüne geçmek ad1na bir mekanizmanın kurulması, sağlık kurumlarının veya hekimlerin web sayfalarında yayınladıkları sağlık bilgileri için Sağlık Bakanlığı’ndan izin alınması, internette sağlık bilgisi araştırırken dikkat edilmesi gereken hususlara basın yayın organlarında yer verilmesi, sağlık kurumlarının, üniversitelerin, sivil toplum kuruluşlarının bireylerin doğru ve güvenli sağlık bilgilerine ulaşabileceği web siteleri oluşturmaları ve erişime açmaları önerilmektedir. Bu araştırmanın sadece İstanbul'da yapılmış olması bir sınırlılık olsa da, bireylerin e-sağlık okuryazarlığı ve siberkondri düzeylerinin demografik özelliklere göre farklılık gösterip göstermediğini; ayrıca e-sağlık okuryazarlığı ile siberkondri düzeyleri arasındaki ilişkiyi ortaya koyması açısından önemlidir. Konuyla ilgili benzer araştırmaların daha geniş bir coğrafyada, daha fazla katılımcıyla ve farklı değişkenlerde dahil edilerek yapılmasının yararlı olacağı düşünülmektedir.

\section{Kaynakça}

Akbolat, Mahmut, Gülcan Kahraman, Gülsün Erigüç ve Hakan Sağlam. "Sağlık Okuryazarlığı Hasta-Hekim İlişkisini Etkiler mi?: Sakarya İlinde Bir Araştırma”. TAF Preventive Medicine Bulletin. 15:4 (2016): 354-362.

Altındiş, Selma, Mustafa Baran İnci, Ferhat Gürkan Aslan ve Mustafa Altındiş. “Üniversite Çalışanlarında Siberkondria Düzeyleri ve İlişkili Faktörlerin İncelenmesi”. Sakarya Tip Dergisi. 8:2 (2018):359-370.

Altınışık, Derya. "İnternet Çağının Hastalığı: Siberkondri”. Erişim 10 Ocak, 2020, https://www.bilimvetekno.com/internet-caginin-hastaligi-siberkondri/.

Andrus, Miranda R. ve Mary T. Roth. "Health Literacy: A Review". Pharmacotherapy: The Journal of Human Pharmacology and Drug Therapy. 22:3 (2002): 282-302.

Batıgün, Ayşegül Durak, Nağme Gör, Burcu Kömürcü ve İpek Şenkal Ertürk. "Siberkondriya Ölçeği (SİBKÖ): Geliştirme, Geçerlik ve Güvenirlik Çalışması”. Dusunen Adam The Journal of Psychiatry and Neurological Sciences. 31:2 (2018):148162.

Can, Abdullah Buğra, Ebru Sönmez, Ferhad Özer, Gözde Ayva, Halit Bacı vd. “Sağlık Arama Davranışı Olarak İnternet Kullanımını İnceleyen Bir Araştırma”. Cumhuriyet Tip Dergisi. 36:4 (2014): 486-494.

Coşkun, Sabahat ve Hatice Bebiş. "Adolesanlarda E-Sağlık Okuryazarlığı Ölçeği: Türkçe Geçerlik ve Güvenirlik Çalışması”. Gülhane Tip Dergisi. 57 (2015): 378384.

Elciyar, Kemal ve Deniz Taşçı. “Siberkondri Ciddiyet Ölçeği’nin Anadolu Üniversitesi İletişim Bilimleri Fakültesi Öğrencilerine Uygulanması”. Abant Kültürel Araştırmalar Dergisi. 2:4 (2017): 231-244.

Ergün, Sibel, Hale Kızıl Sürücüler ve Reyhan Işık. "Ergenlerde E-Sağlık Okuryazarlığı ve Sağlıklı Yaşam Biçimi Davranışları: Balıkesir Örneği”. JAREN. 5:3 (2019):194- 
203.

Ertaş, Handan, Ramazan Kıraç ve Rahime Nur Demir. "Dijital Okuryazarlık ve E-Sağlık Okuryazarlığı Arasındaki İlişkinin İncelenmesi” 3.Uluslararası 13.Ulusal Sağlık ve Hastane İdaresi Kongresi Bildiri Kitabı, Sakarya Üniversitesi, Sakarya, Ekim 10-13, 2019.

Frisch, Anne-Linda, Luca Camerini, Nicola Diviani ve Peter J. Schulz. "Defining and Measuring Health Literacy: How Can We Profit from Other Literacy Domains?”. Health Promotion International. 27:1 (2011):117-126.

Gençer, Ali Görkem, Mehmet Emrah Karadere, Burak Okumuş ve Çiçek Hocaoğlu. "DSM-5'e Giremeyen Tanılar (Kompulsif Satın Alma, Misophonia, Facebook Kıskançlı̆̆1, Pagofaji, Siberkondria, İnternet Bağımlılığı)”. Türkiye Klinikleri Psikiyatri-Özel Konular. DSM-5’in Yeni Tanıları Özel Sayısı (2018): 87-96.

Güven, Durdane Yılmaz, Hülya Bulut ve Sercan Öztürk. "Sağlık Bilimleri Fakültesi Öğrencilerinin Sağlık Okuryazarlığı Düzeylerinin İncelenmesi”. Journal of History Culture and Art Research. 7:2 (2018): 400-409.

Ilgaz, Ayşegül ve Sebahat Gözüm. “Tamamlayıcı Sağlık Yaklaşımlarının Güvenilir Kullanımı için Sağlık Okuryazarlığının Önemi”. Dokuz Eylül Üniversitesi Hemşirelik Fakültesi Elektronik Dergisi. 9:2 (2016): 67-77.

İbrahimoğlu, Özlem, Hülya Saray Kılıç ve Sevinç Mersin. "Fabrika Çalışanlarının Sağlık Okuryazarlığ ve Toplum. 3 (2019): 26-32.

Manganello, Jennifer A. "Health Literacy and Adolescents: A Framework and Agenda for Future Research". Health Education Research. 23:5 (2008): 840-847.

McElroy, Eoin ve Mark Shevlin. "The Development and Initial Validation of the Cyberchondria Severity Scale (CSS)". Journal of Anxiety Disorders. $28: 2$ (2014): 259-265.

McMullan, Ryan D., David Berle, Sandra Arnáez ve Vladan Starcevic. “The Relationships between Health Anxiety, Online Health Information Seeking, and Cyberchondria: Systematic Review and Meta-Analysis". Journal of Affective Disorders. 245 (2019): 270-278.

Norman, Cameron D. ve Harvey A. Skinner. "eHealth Literacy: Essential Skills for Consumer Health in a Networked World". Journal of Medical Internet Research. 8:2:e9 (2006): 1-11.

Norman, Cameron D. ve Harvey A. Skinner. "eHEALS: The eHealth Literacy Scale”. Journal of Medical Internet Research. 8:4:e27 (2006): 1-7.

Nutbeam, Don. Health Promotion Glossary. Geneva: World Health Organization, 1998.

Schwartzberg, Joanne G., Allison Cowett, Jonathan VanGeest ve Michael S. Wolf. "Communication Techniques for Patients with Low Health Literacy: A Survey of Physicians, Nurses, and Pharmacists". American Journal of Health Behavior. 31:1 (2007): S96-S104.

Starcevic, Vladan. "Cyberchondria: Challenges of Problematic Online Searches for 
Health-Related Information". Psychotherapy and Psychosomatics. 86:3 (2017): 129-133.

Starcevic, Vladan ve David Berle. "Cyberchondria: Towards a Better Understanding of Excessive Health-Related Internet Use". Expert Review of Neurotherapeutics. 13:2 (2013): 205-213.

T.C. Sağlık Bakanlığı Temel Sağlık Hizmetleri Genel Müdürlüğü. Sağlı̆̆ın Teşviki ve Geliştirilmesi Sözlü̈̆̈ü. Ankara: T.C. Sağlık Bakanlığı Temel Sağlık Hizmetleri Genel Müdürlüğü, 2011.

Tiritoğlu, Sena. "Diyetisyene Başvuran Bireylerin Beslenme ve Diyet Hakkındaki Düşünceleri ile Siberkondri İlişkisi”. Yüksek Lisans Tezi, T.C. Okan Üniversitesi, 2019.

TÜİK. Erişim 9 Ocak, 2020. http://www.tuik.gov.tr/PreTablo.do?alt_id=1028

Utma, Seçil. "Sağlık Okuryazarlığı Kavramı ve Sağlık Haberlerini Doğru Okumak". IBAD Sosyal Bilimler Dergisi. 5 (2019):223-231.

Uzun, Süleyman Utku. "Pamukkale Üniversitesi Çalışanlarında Siberkondri Düzeyi ve Etkileyen Etmenler”. Uzmanlık Tezi, T.C. Pamukkale Üniversitesi, 2016.

Yılmaz, Medine ve Zeliha Tiraki. "Sağlık Okuryazarlığı Nedir? Nasıl Ölçülür?”. Dokuz Eylül Üniversitesi Hemşirelik Fakültesi Elektronik Dergisi. 9:4 (2016): 142-147.

Zarcadoolas, Christina, Andrew Pleasant ve David S. Greer. "Understanding Health Literacy: An Expanded Model”. Health Promotion International. 20:2 (2005): 195-203. 
İNSAN\&İNSAN, Y1l/Year 7, Say1/Issue 24, Bahar/Spring 2020, 84-96

DOI: https://doi.org/10.29224/insanveinsan.674726

\section{SERKAN DENIZ}

Abstract: Accessing health related information rapidly and easily from the Internet has become possible. Because of this, the concepts of e-health literacy and cyberchondria have become important nowadays. This study aims to assess whether e-health literacy and cyberchondria levels of individuals display a difference according to demographic features or not, and to determine the correlation between e-health literacy and cyberchondria levels. The research was realized in Istanbul between the months of December 2019 - January 2020. The result of the study demonstrated that the e-health literacy levels of participants did not vary statistically according to their age, educational status, marital status or their employment status, however it was found that e-health literacy levels of participants varied statistically according to gender. It was demonstrated that the cyberchondria levels of participants did not vary statistically according to the gender, age, marital status and employment status of the participants, but that they varied statistically according to the participants' educational status. A positive and lowlevel correlation was found between e-health literacy and cyberchondria.

Keywords: e-Health Literacy, Cyberchondria, Internet, Health. 